\title{
Regional Cerebral Blood Flow Statistical Patterns and Psychological Performance in Multi-Infarct Dementia and Alzheimer's Disease
}

\author{
FRANCISCO I. PEREZ, NINAN T MATHEW, DAVID A. STUMP, AND JOHN S. MFYER
}

\begin{abstract}
SUMMARY: Multivariate data analysis statistical procedures were applied to identify regional cerebral blood flow $(r C B F)$ patterns in patients with multiinfarct dementia (M.I.D.) and Alzheimer's disease (A.D.) when compared to a control group (C.). A frontotemporal-parietal pattern was identified for the A.D. group. The M.I.D. group demonstrated a predominant temporalparietal pattern. A discriminant function analysis classified $96 \%$ of the A.D. and C. patients correctly. One hundred percent hit rate was obtained in discriminating between M.I.D. and C. Discrimination of A.D. and M.I.D. obtained $82 \%$ diagnostic accuracy. When the three
\end{abstract}

RÉSUMÉ: Des procédures statistiques d'analyse de données par variances multiples furent appliquées pour identifier les types de rCBF chez les patients atteints de démences secondaires à de multiples infarcissements (M.I.D.) et dans la maladie d'Alzheimer (A.D.), comparés à un groupe contrôle $(C)$. Un pattern fronto-temporo-pariétal fut identifié pour le groupe A.D. Le groupe M.I.D. démontrait un type temporopariétal prédominant. Une analyse de fonctions discriminantes classifiait correctement $96 \%$ des patients A.D. et $C$ Cent pour cent de réussite fut obtenu en discriminant les groupes M.I.D. et $C$ La discrimination des groupes A.D. et M.I.D. donnait $82 \%$ d'exactitude de diagnostic. Quand les trois groupes étaient comparés, le taux

From the Departments of Neurology and Psychiatry. Baylor College of Medicine, and the Baylor-Methodist Center for Cerebrovascular Research, Houston, Texas

This work was supported by Grant NS 09287 from the National Institute of Neurological Diseases and Stroke, and in part from NIH Grant RR-00259 for computational activities.

Reprint Requests to: Francisco I. Perez, Ph.D. Department of Neurology, Baylor College of Medicine, 1200 Moursund Avenue, Houston, Texas 77030 U.S.A. groups were compared the hit rate was 93\%. Mean $r C B F$ and mean relative weight of the gray matter $(W g)$ differences were found when each dementia group was compared with C.M.I.D. and $A . D$. did not differ in mean $r C B F$ but significant differences were found for $W g$, with M.I.D. having greater reduction. The performance on standardized psychological tests of two independent samples of A.D and M.I.D. were compared. The Memory Quotient from the Wechsler Memory Scale was consistently more impaired for the A.D. group. No correlation between degree of psychological impairment and $r C B F$ or $W g$ reduction was found.

de succès était de $83 \%$. Des différences furent obtenues quant au rCBF moyen et quant au poids moyen relatif de la substance grise $(W g)$ quand chaque groupe de démence fut comparé au groupe contrôle. Les groupes M.I.D. et A.D. ne différaient pas en ce qui concerne le rCBF moyen mais des différences significatives furent trouvées pour le $\mathrm{Wg}$, le groupe M.I.D. ayant la plus grande réduction. La performance aux tests psychologiques standardisés de deux groupes A.D. et M.I.D. indépendants fut comparée. Le quotient de mémoire mesuré par l'échelle de mémoire de Wechster fut constamment plus bas dans le groupe A.D. Nous n'avons trouvé aucune corrélation entre le degré d'altération psychologique et la réduction de $r C B F$ ou de $W g$
Reduction of cerebral blood flow $(\mathrm{CBF})$ in organic dementias has long been recognized (Obrist et al., 1970). Research studies have also established that this reduction is not attributed solely to normal aging (Kety, 1956; Sokoloff, 1953). Regional cerebral blood flow (rCBF) studies in dementia report a selective regional reduction of blood flow (Obrist et al., 1970). Ingvar (1970), applying a $20 \%$ reduction from the patient's mean CBF value as a criterion for regional decrease, found a frontotemporal pattern of reduction in a group of patients classified as "senile dementia". In a "presenile dementia" group, he found a wider scatter with less fronto-temporal reduction and more posterior temporal and parietal foci. Obrist et al., (1970) have similarly found consistent focal reduction in the fronto-temporal region in a group of patients with "senile dementia" and a more variable regional reduction in a group classified as "presenile dementia". These findings suggest that different underlying pathological processes can produce different and distinct rCBF patterns. The implications for clinical diagnostic utility of $\mathrm{rCBF}$ patterns are obvious.

It is generally accepted that both "presenile" and "senile" dementia are forms of Alzheimer's disease (A.D.) with the same clinical manifestations and histopathological findings (Hachinski et al., 1974). In hypertensive patients or those associated with other risk factors for cerebrovascular disease such as diabetes, hyperlipidemia, and disseminated intravascular coagulation, multiple episodes of cerebral ischemia and infarctions may occur 
with cumulative and hence progressive neurological deficits with subsequent mental deterioration. This form of dementia has been appropriately termed multi-infarct dementia (M.I.D.) by Hachinski, et al., (1974). Recently, Perez et al., (1975abcd) have reported different neuropsychological patterns of functioning in A.D. and M.I.D. using multivariate statistical. procedures.

A consistent feature in dementia is a neuropsychological deterioration, particularly in memory and intellectual functioning. A correlation between the severity of mental impairment in the dementias and reductions of $\mathrm{CBF}$ and metabolism have been reported (Obrist et al., 1970; Lassen et al., 1957; 1960). Simard et al., (1971) as well as Obrist et al., (1970) found a positive correlation between the decrease in mean hemispheric $\mathrm{CBF}$ and the degree of dementia in groups of patients with A.D. However, more recently, Hachinski et al., (1975) found no correlation between the degree of dementia and CBF in a primary degenerative group. These studies have used different procedures for assessing behavioral performance. Rating scales, psychiatric interviews and global non-standardized psychological procedures are primarily used. This approach is in direct opposition to the development and use of standardized psychological procedures which offer quantitative results. The conflicting results are probably due to a lack of standardization in the measurement of behavioral performance.

The purpose of the present study is to apply multivariate data analysis statistical procedures (Cooley and Lohnes, 1971) to assess whether certain rCBF patterns can be identified in patients with M.I.D. and A.D. when compared to a control group (C). The performance on standardized psychological tests of two independent samples of patients are compared. A correlational study ranking degree of impairment on the psychological tests and mean $\mathrm{CBF}$ is reported on a subset of patients where the $\mathrm{CBF}$ and psychological measures were obtained on the same hospital admission.
Patients. Fifty-seven patients with a mean age of 67 ranging from 44 to 87 years were included in the $\mathrm{rCBF}$ study. The criteria presented by Perez et al., (1975a) was used in establishing the diagnosis and classifying the patients as M.I.D. $(\mathrm{N}=$ 22) and $\operatorname{AD}(N=20)$. The control subjects $(\mathrm{N}=15)$ were patients with various neurological disorders, but without dementia or focal cerebral lesions.

\section{Clinical-Diagnostic Classification} Criteria. The diagnostic evaluation included the results of the medical and neurological examination as well as electroencephalograms, brain aorto-cranial angiograms, pneumoencephalograms, and radioisotope ateriograms. The rCBF data as well as the neuropsychological results presently reported were not included in the evaluation. A team of three neurologists independently classified the patients into the diagnostic groups on the basis of the complete clinical and laboratory evaluation. In all cases, systemic disorders causing dementia were excluded such as neurosyphilis, vitamin B deficiency, folate deficiency, uremia and hypothyroidism. In three A.D. cases and two M.I.D. cases the diagnosis was confirmed by necropsy. All patients participating in the study were admitted to the Baylor-Methodist Center for Cerebrovascular Research and the majority were followed at least a year or more with periodic re-examinations.

The patients were classified into the following two groups of dementia:

Multi-infarct dementia (M.I.D.): The dementing process in these patients was associated with documented risk factors for cerebrovascular disease, particularly a longstanding history of hypertension (Kannel et al., 1971). The clinical course of the dementia was characterized by episodic minor or major strokes with cumulative worsening of mentation and neurological status.

Alzheimer's Disease (A.D.): These patients presented with a history of chronic progressive dementing pro- cess without risk factors or evidence of cerebrovascular disease. The clinical course in these patients was not characterized by episodic worsening of mentation as typically occurs in patients with cerebrovascular disease. There was no history of transient cerebral ischemic attacks, but a steadily progressive deterioration of intellectual functions.

rCBF Measurement Procedures: rCBF was measured utilizing the intra-arterial radioisotope technique (Lassen and Ingvar, 1961) and gamma camera (Mathew et al., 1972; Mathew et al., 1974). Details of the technique and reproducibility of measurements of rCBF after intracarotid injection of ${ }^{\mathbf{1 3 3}}$ Xenon have been reported (Heiss et al., 1972). Short term variations in $\mathrm{rCBF}$ and inter-regional differences have been established for the method (Heiss, 1973; Prosenz et al., 1974), with intracarotid injection of ${ }^{133}$ Xenon the gamma camera gives rCBF values comparable to the multiple probe system (Klassen et al., 1971).

The clearance of ${ }^{133} \mathrm{Xe}$ was monitored from the lateral surface of the head for 10 minutes. The data was stored on magnetic tape. A computer analyzed the clearance curve of the radioisotope and provided automatic print-out of $\mathrm{rCBF}$ expressed as $\mathrm{rCBF}$ for 10 minutes $\left(\mathrm{rCBF}^{10}\right)$, flow in gray matter $(\mathrm{Fg})$, flow in white matter $(\mathrm{Fw})$ and relative weight of gray matter $(\mathrm{Wg})$ and relative weight of white matter $(\mathrm{Ww})$ (Mathew et al., 1972; 1974). rCBF from 13 different regions of the right hemisphere were obtained in each case. Arterial blood pressure and arterial $\mathrm{PCO}_{2}\left(\mathrm{PaCo}_{2}\right)$ were recorded during the procedure.

Neuropsychological Procedures: Two independent samples of patients with the diagnosis of A.D. and M.I.D. were obtained. The first sample consisted of 26 patients ranging in age from 45 to 85 years with a mean age of 65 years. Ten were classified as A.D. and 16 as M.I.D. The second sample consisted of 31 patients ranging in age from 44 to 83 with a mean age of 63 years. This sample is a subset of patients included in the rCBF study. Seventeen 
TABLE I

RESULTS OF ANALYSIS OF VARIANCE

\begin{tabular}{|c|c|c|c|c|c|c|c|}
\hline \multirow[t]{2}{*}{ Variables } & \multicolumn{2}{|c|}{ Alzheimer's } & \multicolumn{2}{|c|}{ Multi-infarct } & \multicolumn{2}{|c|}{ Control } & \multirow[t]{2}{*}{ F-value } \\
\hline & Mean & S.D. & Mean & S.D. & Mean & S.D. & \\
\hline $\mathrm{rCBF}^{++}$ & 34.11 & 5.90 & 31.99 & 5.52 & 49.12 & 4.55 & $53.19 *$ \\
\hline ?low-gray $(\mathrm{Fg})^{++}$ & 69.26 & 32.87 & 56.29 & 16.80 & 75.70 & 8.19 & N.S. ** \\
\hline Neight-gray (Wg) & 48.62 & 9.93 & 38.54 & 8.94 & 54.40 & 7.01 & $72.58 *$ \\
\hline ?low-white $(\mathrm{Fw})^{++}$ & 20.23 & 2.62 & 17.31 & 3.82 & 20.62 & 3.61 & N.S.** \\
\hline Neight-white (Ww) & 48.93 & 13.67 & 51.45 & 8.94 & 48.53 & 7.00 & N.S.** \\
\hline
\end{tabular}

+ Regional measurements in each patient were averaged

$++\mathrm{ml} / 100 \mathrm{gm} / \mathrm{min}$

* $\mathrm{P}<.001$

** N.S. = not significant

TABLE II

RESULTS OF SCHEFFE' TEST TO DETERMINE SIGNIFICANCE

\begin{tabular}{|c|c|c|c|}
\hline & ETWEEN SPEC & GROUPS & \\
\hline Jariables & MID VS $A D$ & MID vs $C$ & $\mathrm{AD}$ vs $\mathrm{C}$ \\
\hline$r \mathrm{CBF}$ & N.S. & $p<.001$ & $p<.001$ \\
\hline $\mathrm{Wg}$ & $p<.01$ & $p<.01$ & $\mathrm{p}<.01$ \\
\hline
\end{tabular}

$\begin{array}{ll}\text { v.S. = Not significant } & \mathrm{rCBF}=\text { regional cerebral blood flow } \\ \mathrm{vg}=\text { gray matter weight } & \mathrm{MID}=\text { multi-infarct dementia } \\ \mathrm{z}=\text { control group } & \mathrm{AD}=\text { Alzheimer's disease }\end{array}$

$\mathrm{AD}=$ Alzheimer's disease, $\mathrm{MID}=$ multi-infarct dementia, $\mathrm{c}=$ control group. were classified as A.D. and 14 as M.I.D.

The Wechsler Adult Intelligence Scale (WAIS) (Perez et al., 1975b) and the Wechsler Memory Scale (WMS) (Perez et al., 1975c) were individually administered to each patient participating in the neuropsychological study. A Full Scale IQ (FIQ), Verbal IQ (VIQ), Performance IQ (PIQ) and Memory Quotient (MQ) was computed for each patient.

Results. Blood flow study Analysis of Variance and Scheffé Test: In order to assess any statistizal differences among the three groups, an analysis of variance (ANOVA) was performed. Table 1 shows the results. Significant differences were found for the mean $\mathrm{rCBF}$ and the mean relative gray matter $(\mathrm{Wg})$. A series of Scheffé Tests for ad hoc comparisons were performed in order to determine any specific differences between the groups for each variable found significant by the ANOVA. Table 2 presents these findings. Significant differences were found for the mean $\mathrm{rCBF}$ variable between M.I.D. and C. as well as for A.D. and C. No significant differences were found between M.I.D. and A.D. For Wg, significant differences were found for the specific paired comparisons combination between each group.

Discriminant function analysis and Maximum $R$-square improvement stepwise regression: In the present section we were concerned with analyzing the multiple rCBF measurements obtained for each patient in the three groups. The Statistical Analysis System Computer program for multivariate analysis developed at North Carolina State University was used. In a multivariate analysis the multiple variables are considered in combination as a system of measurement (Cooley and Lohnes, 1971). The results are presented first for 
the analysis performed on the three groups and then for every pair of diagnostic combinations.

1. A.D., M.I.D. and C. A discriminant function analysis was performed on the $13 \mathrm{rCBF}$ predictor variables and the three groups. The multiple discriminant analysis produced a set of coefficients or weights for the various dependent measures which best separated or discriminated the three different diagnostic categories. The between group variance was maximized relative to the within group variance. A composite discriminant predictor score was then computed for each patient based on his or her rCBF values and the optimal lambda weightings ( $\lambda$ ) for each variable. Based on this composite score, each patient was then classified into one of the three diagnostic categories.

A Chi-square $\left(X^{2}\right)$ test was then performed in order to measure the degree of separation of the probability distributions of the three groups. The $X^{2}$ was significant $\left(\mathrm{X}^{2}=329.43,183\right.$ d.f., $\left.\mathrm{p}<.001\right)$ thus the within covariance matrices were used in performing the discriminant function analysis. Table 3 presents the assignment of patients to each group based on the $13 \mathrm{rCBF}$ predictor variables. The hit rate of the discriminant function analysis in classifying patients as A.D., M.I.D. or $\mathrm{C}$. by the $13 \mathrm{rCBF}$ values alone was $93 \%$.

Figure 4 shows the arbitrary numbering of the 13 regions of the brain from which $\mathrm{rCBF}$ values were obtained. Each of these regions is an independent variable. In order to determine which combination of the $13 \mathrm{rCBF}$ variables produced the "best" statistical model that discriminated among the three groups a Maximum R-square $\left(\mathrm{R}^{2}\right)$ improvement stepwise regression was performed. This technique was applied in order to find which regions of the 13 rCBF measures obtained should most likely be included in a regression model. It finds first the one variable model producing the highest $\mathrm{R}^{2}$ statistic. $\mathrm{R}^{2}$ is the square of the multiple correlation coefficient and is equal to the proportion of the dependent variable's total variance which is accounted for by the model. Then another variable, the one which would yield the greatest increase in $\mathrm{R}^{2}$ is added. Once this two-variable model is obtained, each of the variables in the model is compared to each variable not in the model. For each comparison, the procedure determines if removing the variable in the model and replacing it with the presently excluded variable would increase $\mathrm{R}^{2}$. After all the possible comparisons have been made, the switch which produces the largest increase in $R^{2}$ is made. Comparisons are made again, and the process continues until the procedure finds that no switch could increase $\mathrm{R}^{2}$. The two-variable model thus settled on is considered the "best" two-variable model the technique can find. The technique then adds a third variable to the model, according to the criteria used in adding the second variable. The comparing-and-switching process is repeated and the "best" threevariable model is found and so forth. Variables are added one by one to the model until all variables are included. Any two models can be compared for predictive accuracy by testing the difference between their $\mathrm{R}^{2} \mathrm{~s}$ with $\mathrm{F}$ tests.
Table 4 presents the maximum $\mathrm{R}^{2}$ improvement stepwise regression for all groups. The "best" model discriminating between the three groups was the three variable model which included regions 6,8 , and 9 (frontal and parietal) accounting for $53 \%$ of the variance. Addition of any other region to the model did not increase $\mathbf{R}^{2}$ significantly. The 13 region model accounted for $64 \%$ of the variance. No significant difference in $\mathrm{R}^{2}$ was found between the three region model and the 13 region model.

2. A.D. and C. The $\mathrm{X}^{2}$ performed in order to measure the degree of separation of the probability distributions of A.D. and C. was significant $\left(\mathrm{X}^{2}=156.11,105\right.$ d.f., $\mathrm{p}<$ .01 ), thus the within covariance matrices were used in performing the discriminant function analysis. The two groups were found to be discrete. Table 5 presents the assignment of patients to each diagnostic group. The discriminatory hit rate was $96 \%$.

Table 6 presents the maximum $\mathbf{R}^{2}$ improvement stepwise regression for A.D. and C. The "best" discriminating model was the three variable model including regions 3,6 , and 9 (fronto-temporal-parietal) ac-

TABLE IV

MAXIMUM R-SQUARE IMPROVEMENT STEPWISE REGRESSION FOR

ALZHEIMERS DISEASE, MULTI-INFARCT DEMENTIA, AND CONTROL GROUPS

Number
in Model
1
2
3
4
5
6
7
8
9
10
11
12
13

rCBF Variables in Model
6,9
$6,8,9$
$6,8,9,13$
$3,6,9,12,13$
$3,6,8,9,12,13$
$3,6,8,9,10,12,13$
$2,3,6,8,9,10,12,13$
$2,3,4,6,8,9,10,12,13$
$1,2,3,4,6,8,9,10,12,13$
$1,2,3,4,6,8,9,10,11,12,13$
$1,2,3,4,6,7,8,9,10,11,12$,
13
$1,2,3,4,5,6,7,8,9,10,11$,
12,13

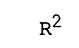

0.4027

0.4710

0.5267

0.5563

0.5948

0.6116

0.6183

0.6318

0.6369

0.6382

0.6402

0.6403

12,13

0.6404
F-Value for

Increment

$\mathrm{p}$

d.f.

5.617

5.0636

2.7925

3.8889

1.7320

0.6387

1.3918

0.5204

0.1287

0.1942

0.0094

0.0092 
TABLE V

DISCRIMINANT FUNCTION CLASSIFICATION

FOR AD AND C

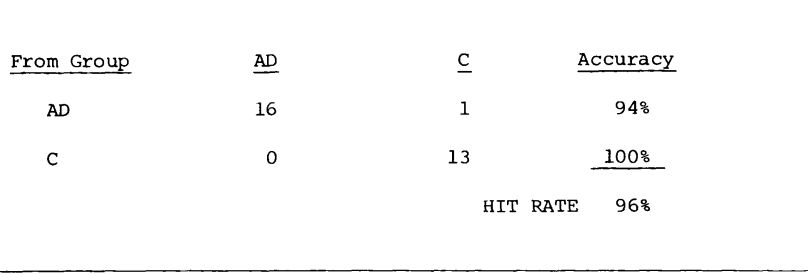

$\mathrm{AD}=\mathrm{Alzheimer}$ 's disease, $\quad \mathrm{c}=$ control group

TABLE VI

MAXIMUM R-SQUARE IMPROVEMENT STEPWISE REGRESSION

FOR ALZHEIMERS DISEASE AND CONTROL GROUPS

Number

in Model

1

2

3

4

5

6

7

8

9

10

11

12

13

$\begin{array}{lcccr}\text { rCBF Variables in Model } & \mathrm{R}^{2} & \begin{array}{l}\text { F-Value for } \\ \text { Increment }\end{array} & \mathrm{p} & \mathrm{d} . \mathrm{f} \\ 9 & 0.5229 & 6.125 & <.025 & 1,27 \\ 9,13 & 0.6111 & 6.813 & <.025 & 1,26 \\ 3,6,9 & 0.6915 & 4.162 & \text { N.S. } & 1,25 \\ 3,6,9,13 & 0.7352 & 3.468 & \text { N.S. } & 1,24 \\ 3,6,8,9,13 & 0.7685 & 2.219 & \text { N.S. } & 1,23 \\ 2,3,6,8,9,13 & 0.7887 & 0.242 & \text { N.S. } & 1,22 \\ 1,2,3,6,8,9,13 & 0.7910 & 0.245 & \text { N.S. } & 1,21 \\ 1,2,3,6,8,9,11,13 & 0.7934 & 0.088 & \text { N.S. } & 1,20 \\ 1,2,3,4,6,8,9,11,13 & 0.7943 & 0.022 & \text { N.S. } & 1,19 \\ 1,2,3,4,6,8,9,10,11,13 & 0.7947 & 0.026 & \text { N.S. } & 1,18 \\ 1,2,3,4,5,6,8,9,10,11,12,13 & 0.7950 & 0.7951 & \text { N.S. } & 1,17 \\ 1,2,3,4,5,6,7,8,9,11,12,13 & 0.7952 & 0.007 & \text { N.S. } & 1,16 \\ 1,2,3,4,5,6,7,8,9,10,11,12,13 & 0.08 & & \end{array}$

TABLE VIII

MAXIMUM R-SQUARE IMPROVEMENT STEPWISE REGRESSION

FOR MULTI-INFARCT DEMENTIA AND CONTROL GROUPS

Number
in Model
1
2
3
4
5
6
7
8
9
10
11
12
13

TABLE VII

DISCRIMINANT FUNCTION CLASSIFICATION FOR MID AND C

\begin{tabular}{ccccc} 
From Group & MID & & C & Accuracy \\
\hline MID & 17 & 0 & $100 \%$ \\
C & 0 & 13 & $100 \%$ \\
& & HIT RATE & $100 \%$
\end{tabular}

MID $=$ multi-infarct dementia, $\mathrm{c}=$ control group counting for $69 \%$ of the variance. Addition of any other region to the model did not increase $\mathrm{R}^{2}$ significantly. The 13 region model accounted for $80 \%$ of the variance. No significant difference in $\mathrm{R}^{2}$ was found between the three region model and the 13 region model.

3. M.I.D. and C. The $\mathrm{X}^{2}$ was significant $\left(X^{2}=177.89,105\right.$ d.f., $p<.01)$ thus the within covariance matrices were used in performing the discriminant function analysis. Table 7 presents the assignment of patients to each diagnostic group. The discriminatory accuracy obtained was $100 \%$.

The maximum $\mathbf{R}^{2}$ improvement stepwise regression for M.I.D. and C. is presented in Table 8 . The "best" model was the three variable model including regions 3,9 , and 13 (temporo-parietal) which accounted for $82 \%$ of the variance. Addition of any other region to the model did not increase $\mathrm{R}^{2}$ significantly. The 13 region model accounted for $88 \%$ of the variance.

4. M.I.D. and A.D. The $\mathrm{X}^{2}$ test was not significant $\left(\mathrm{X}^{2}=110.23,91\right.$ d.f., $p<.05$ ), thus the pooled covariance matrix was used in the discriminant function analysis. The two groups tended to overlap in their probability distribution. Table 9 presents the discriminant function classification. The hit rate obtained was $82 \%$.

Table 10 presents the maximum $\mathbf{R}^{\mathbf{2}}$ improvement stepwise regression. The "best" model found by the technique was the one variable model which included region 13 which accounted for only $22 \%$ of the variance. No other variable added to the model increased $R^{2}$ significantly. 
MEAN COMPARISON BETWEEN AD \& MID - FIRST SAMPLE

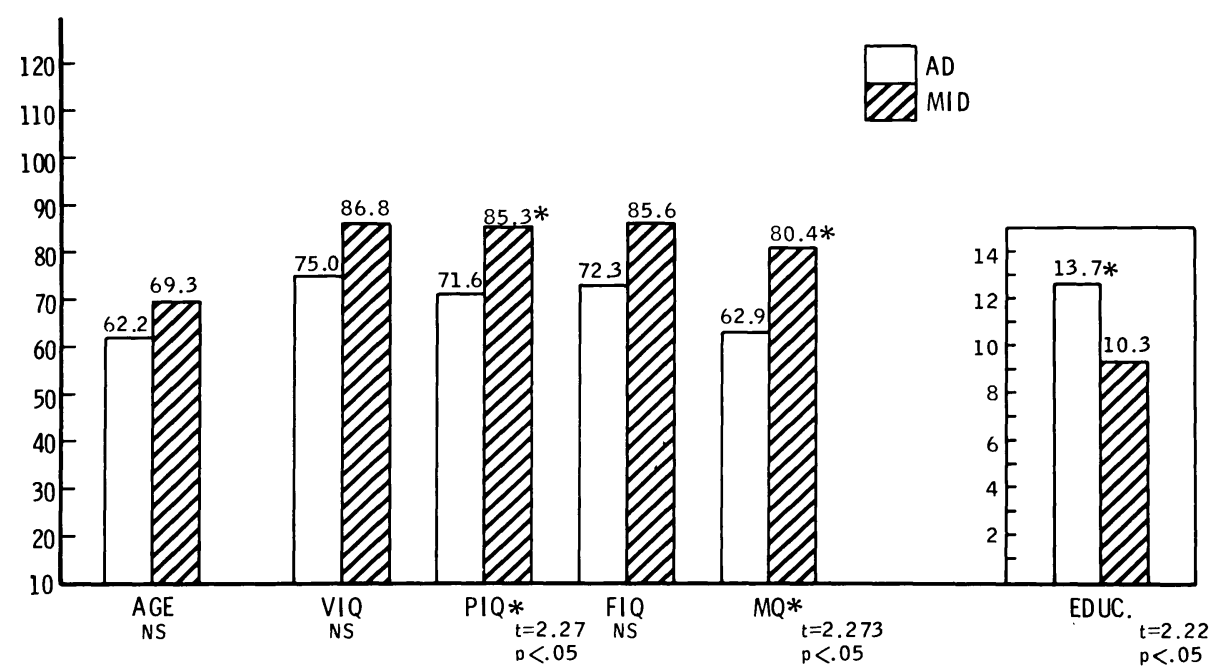

Figure 1-Mean Comparison between A.D. and M.I.D. - First Sample.

A.D. = Alzheimer's disease, M.I.D. = multi-infarct dementia, VIQ $=$ verbal intelligence quotient, PIQ =performance intelligence quotient, FIQ = full scale intelligence quotient, $\mathrm{MQ}=$ memory quotient.

MEAN COMPARISON BETWEEN AD \& MID - SECOND SAMPLE

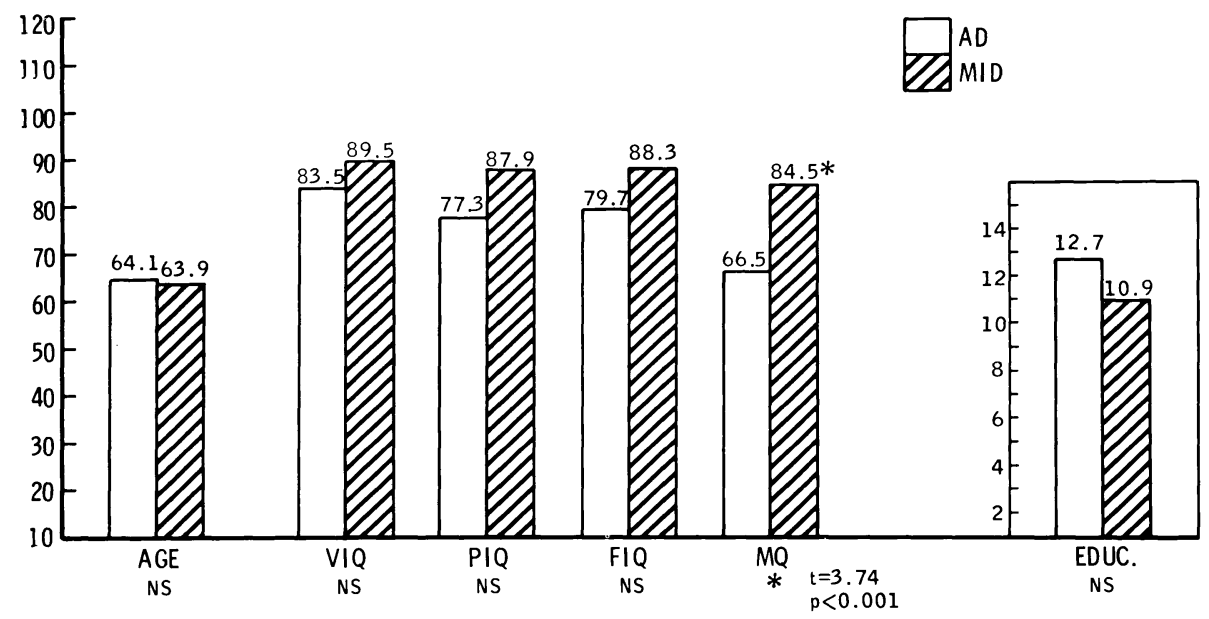

Figure 2-Mean Comparison Between A.D. and M.I.D. - Second Sample. A.D. = Alzheimer's disease, M.I.D. = multi-infarct dementia, VIQ = verbal intelligence quotient, $\mathrm{PIQ}=$ performance intelligence quotient, $\mathrm{FIQ}=$ full scale intelligence quotient, $\mathrm{MQ}=$ memory quotient.

Psychological study. Figure 1 shows the mean comparison between A.D. and M.I.D. - first sample for each measurement obtained. Statistical differences were found between the groups for Performance IQ (PIQ) and Memory Quotient (MQ) with the A.D. group performing significantly lower. It is interesting to note that significant differences were found though the A.D. group was bette educated and consistently per formed lower on all the psychologi cal measures, significant statistica difference was only found for the MQ measure. Figure 3 shows the within group performance for th $\epsilon$ second sample. The M.I.D. grour comparison of MQ with each IC measure was consistent. However the A.D. group showed an impairec MQ and PIQ performance wher compared to the within group VIC and FIQ.

Correlation between psychological performance and cerebral blood flow: In order to assess the relationship of the degree of psychological impairment and $\mathrm{CBF}$ reduction, a series of Spearman rank correlation (rho) were computed. This statistic is a measure of association which requires that both variables, in this case psychological and CBF, be measured in an ordinal scale so that the individuals under study can be ranked in two ordered series. The MQ and PIQ performance were chosen as the psychological variables. Mean $\mathrm{rCBF}, \mathrm{Fg}$ and $\mathrm{Wg}$ values were used as the blood flow variables.

WITHIN GROUP MEAN COMPARISONS MQ vs. VIQ, PIQ \& FIQ - Second Sample

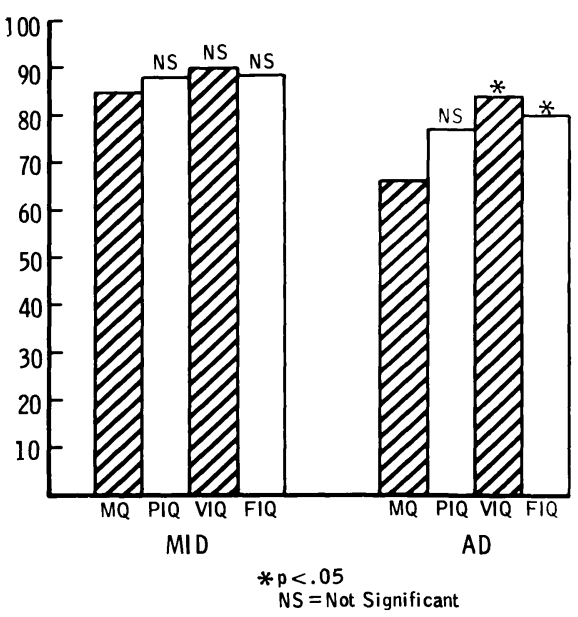

Figure 3-Within Group Mean Comparisons MQ vs. VIQ, PIQ and FIQ Second Sample.

A.D. =Alzheimer's disease, M.I.D. = multi-infarct dementia, VIQ $=$ verbal intelligence quotient, PIQ =performance intelligence quotient, FIQ = full scale intelligence quotient, MQ $=$ memory quotient. 


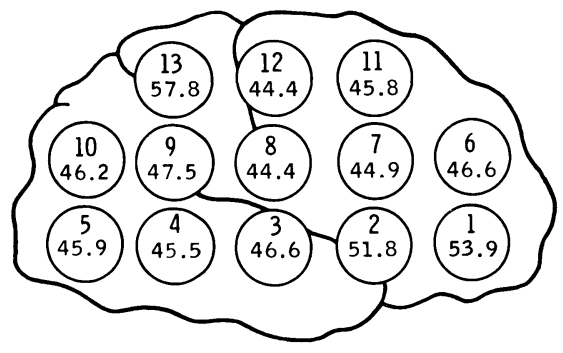

Figure 4-Mean rCBF Values for the Control Group $(\mathrm{N}=15)$.

$\mathrm{rCBF}=$ regional cerebral blood flow.

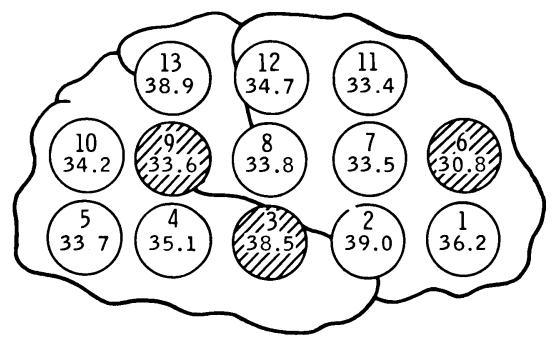

Figure 5-Mean $\mathrm{rCBF}$ Values for the Alzheimer's Group $(\mathrm{N}=20)$.

$\mathrm{rCBF}=$ regional cerebral blood flow

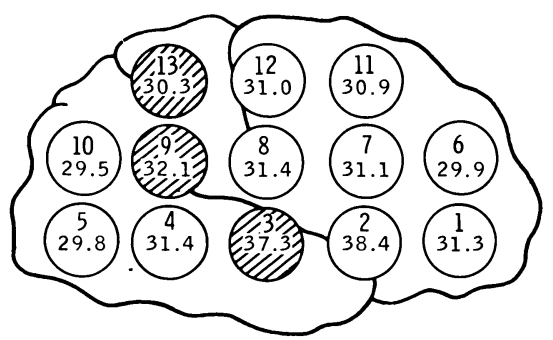

Figure 6-Mean $\mathrm{rCBF}$ Values for the Multi-Infarct Group ( $\mathrm{N}=22$ ).

$\mathrm{rCBF}=$ regional cerebral blood flow

Tables 11 and 12 show the results. No significant correlation between degree of psychological impairment and $\mathrm{CBF}$ reduction on any of the variables was found for the two disease groups.

\section{DISCUSSION}

Advancing chronological age in man does not necessarily imply progressive reduction of cerebral blood flow, oxygen delivery, energy production and dementia (Kety, 1956; Sokoloff, 1953). Studies of carefully categorized groups of elderly patients indicate, on the contrary, that it is the increasing coincidence of associated cerebral disease processes, such as cerebral atherosclerosis of parenchymatous

TABLE IX

DISCRIMINANT FUNCTION CLASSIFICATION

FOR AD AND MID

\begin{tabular}{|c|c|c|c|}
\hline From Group & $\underline{A D}$ & MID & Accuracy \\
\hline$A D$ & 13 & 4 & $76 \%$ \\
\hline MID & 2 & 15 & $88 \%$ \\
\hline & & HIT & $82 \%$ \\
\hline
\end{tabular}

$\mathrm{AD}=\mathrm{Alzheimer}$ 's disease, $\mathrm{MID}=$ multi-infarct dementia

TABLE $X$

MAXIMUM R-SQUARE IMPROVEMENT STEPWISE REGRESSION

FOR ALZHEIMERS DISEASE AND MULTI-INFARCT DEMENTIA GROUPS

\begin{tabular}{|c|c|c|c|c|}
\hline $\begin{array}{l}\text { Number } \\
\text { in Model }\end{array}$ & rCBF Variables in Model & $\mathrm{R}^{2}$ & $\begin{array}{l}\text { F-Value for } \\
\text { Increment }\end{array}$ & $\mathrm{p}$ \\
\hline 1 & 13 & 0.2158 & & \\
\hline 2 & 11,13 & 0.2775 & 2.767 & N.S. \\
\hline 3 & $2,11,13$ & 0.3563 & 3.665 & N.S. \\
\hline 4 & $1,2,11,13$ & 0.3880 & 1.502 & N.S. \\
\hline 5 & $1,2,3,11,13$ & 0.3948 & 0.315 & N.S. \\
\hline 6 & $1,2,3,4,11,13$ & 0.4099 & 0.689 & N.S. \\
\hline 7 & $1,2,3,4,10,11,13$ & 0.4220 & 0.545 & N.S. \\
\hline 8 & $1,2,3,4,9,10,11,13$ & 0.4274 & 0.236 & N.S. \\
\hline 9 & $1,2,3,4,7,9,10,11,13$ & 0.4301 & 0.114 & N.S. \\
\hline 10 & $1,2,3,4,7,9,10,11,12,13$ & 0.4334 & 0.140 & N.S. \\
\hline 11 & $1,2,3,4,6,7,9,10,11,12,13$ & 0.4355 & 0.082 & N.S. \\
\hline 12 & $1,2,3,4,6,7,8,9,10,11,12,13$ & 0.4356 & 0.003 & N.S. \\
\hline 13 & $1,2,3,4,5,6,7,8,9,10,11,12,13$ & 0.4356 & 0.003 & N.S. \\
\hline
\end{tabular}

atrophy of the brain, that account for the reduction of cerebral blood flow and energy production rather than advancing age itself (Meyer et al., 1975). The present results are consistent with previous findings (Obrist et al., 1970; Ingvar, 1970). Significant reduction of mean $\mathrm{rCBF}$ was found for both A.D. and M.I.D. groups when compared to a control group. This reduction was more significant for the M.I.D. group. It was also found that relative weight of the gray matter $(\mathrm{Wg})$ was reduced in both A.D. and M.I.D., but to a greater extent in M.I.D. Previous studies by Obrist et al., (1970), Ingvar (1970), and Hachinski et al., (1975), consistently demonstrated the Wg reduction in organic dementia. Hachinski et al., (1975) analyzed two comparable diagnostic groups to those presently studied. They found that both groups (A.D. and M.I.D.) showed a significant decrease in the $\mathrm{Wg}$ when compared to a control. They interpreted their results as indicating a considerable loss of func- 
SPEARMAN RANK ORDER CORRELATION BETWEEN NEUROPSYCHOLOGICAL AND CEREBRAL BLOOD FLOW DATA FOR ALZHEIMER'S DISEASE
SPEARMAN RANK ORDER CORRELATION BETWEEN NEUROPSYCHOLOGICAL AND CEREBRAL BLOOD FLOW DATA FOR MULTI-INFARCT DEMENTIA

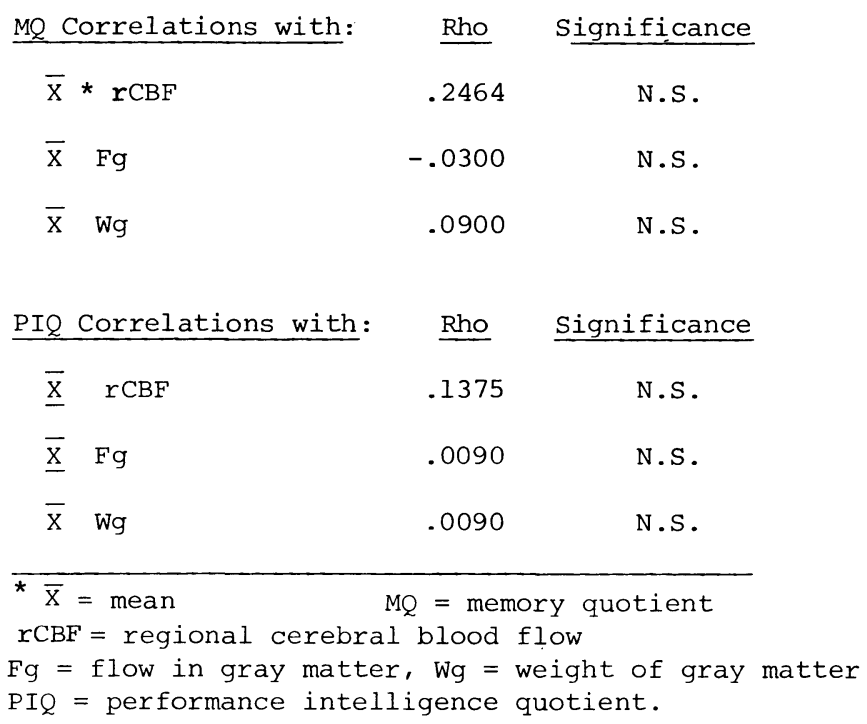

\begin{tabular}{|c|c|c|}
\hline MQ Correlations with: & Rho & Significance \\
\hline $\bar{x} * r \mathrm{CBF}$ & .2143 & N.S. \\
\hline$\overline{\mathrm{X}} \mathrm{Fg}$ & .1108 & N.S. \\
\hline$\overline{\mathrm{X}} \quad \mathrm{Wg}$ & .1036 & N.S. \\
\hline PIQ Correlations with: & Rho & Significance \\
\hline$\overline{\mathrm{x}} \quad \mathrm{rCBF}$ & .1036 & N.S. \\
\hline$\overline{\mathrm{X}} \mathrm{Fg}$ & -.3428 & N.S. \\
\hline$\overline{\mathrm{X}} \quad \mathrm{Wg}$ & .0250 & N.S. \\
\hline \multicolumn{3}{|c|}{$\begin{array}{l}M Q=\text { memory quotient } \\
\text { ebral blood flow } \\
\text { atter, Wg = weight of gray matter } \\
\text { ntelligence quotient. }\end{array}$} \\
\hline
\end{tabular}

tioning gray matter relative to white matter in both M.I.D. and primary degenerative dementia. The present results give additional support to their findings. In addition, it shows that the $\mathrm{Wg}$ reduction is more significant in M.I.D. than A.D.

The results of the discriminant function analysis performed on the $13 \mathrm{rCBF}$ predictor variables and the three diagnostic groups as well as for every pair of diagnostic combinations show that $\mathrm{rCBF}$ measurements are potentially useful in the differential diagnosis of A.D. and M.I.D. (see Tables 3, 5, 6, and 9). Excellent discriminatory accuracy was obtained in differentiating among and between the three groups. The M.I.D. and C. as well as A.D. and C. groups were found to be discrete. It is interesting to note that when comparing the two dementia groups (A.D. and M.I.D.) they tended to overlap in their probability distributions. The valid positive hit rate for discriminating A.D. and M.I.D. was $82 \%$. It is more difficult to separate the two dementia groups than to separate each from a control group. However, $82 \%$ discriminatory accuracy is quite respectable. Further replication studies are needed in order to demonstrate the predictive validity of the present findings.

For theoretical as well as clinical purposes it is important to detect possible patterns of rCBF distribution for the three groups. In order to determine which combination of the 13 rCBF measures produced the "best" statistical model that discriminated the three diagnostic groups a series of maximum $\mathrm{R}^{2} \mathrm{im}$ provement stepwise regression analyses were performed. This powerful multivariate analysis of regression technique supplements concepts of statistical significance with additional information concerning the relative efficiency of a particular model (i.e., proportion of variance accounted for by model) in discriminating the groups. This analytic technique, in addition to finding the "least square weights" for the predictor variables in each model, also generates the coefficient of determination $\left(\mathbf{R}^{2}\right)$ for each model. The task is to trim away useless predictor information (i.e., insignificant sources of variance) and arrive at the simplest representation of the data without reducing the discriminatory accuracy. If a simple model and a less simple model can estimate sam- ple means equally well, the estimates of the simpler model will, on the average, be closer to the parameter means than those produced by the less simple one (Ward and Jennings, 1973). The first step was to identify the "best" (i.e., simplest) statistical model discriminating among the three groups (see Table 4). The three variable model including regions 6,8 , and 9 (frontoparietal) was found to be the "best" model. This model accounted for $53 \%$ of the variance.

Having identified the "best" statistical model discriminating among the three groups, the next step was to identify the simplest model for each pair of diagnostic combinations (see Tables 6, 8, and 10). When the A.D. and C. groups were compared, the "best" model was the three variable model including regions 3,6 , and 9 . This model accounted for $69 \%$ of the variance. Figure 5 shows that this pattern includes rCBF measures from the fronto-temporal-parietal regions. This is consistent with previous findings (Obrist et al., 1970; Ingvar, 1970).

Comparison of M.I.D. and C. revealed that the "best" model was 
the three variable model including regions 3,8 , and 13 . This model accounted for $82 \%$ of the variance. Figure 6 shows that the rCBF pattern for the M.I.D. group includes primarily temporal-parietal regions.

The "best" model differentiating the two dementing groups (M.I.D. and A.D.) was the one variable model including region 13 (parietal) accounting only for $22 \%$ of the variance. Addition of the remaining twelve regions increased the accounted variance to $44 \%$. This increment was not significant. These two groups were more simply discriminated by region 13 .

Disorders of memory are a characteristic and often a prominent feature of dementia. Karp (1974) considers memory loss as a logical point for the clinical analysis of disorders of mental functioning. The present psychological findings demonstrate that the MQ was consistently reduced in both groups and particularly in the A.D. group when compared to the M.I.D. This finding was replicated in two independent samples. Previous studies from our neuropsychology laboratory (Perez et al., 1975c) have demonstrated that it was possible to discriminate the two dementia groups by the MQ. The memory performance is consistent with the rCBF findings including the temporal region (no. 3) in the simplest model for both dementia - groups. It appears that specific regional blood flow reduction is related to specific behavioral impairment (Baer et al., 1976).

Recent studies have reported that the concentration of neurofibrillary tangles and neuritic or senile plaques found at postmortem examination in A.D. corresponded with the degree of psychometric impairment (Tomlinson et al., 1970; Roth et al., 1966), Terry and Wisniewski (1970) report that in A.D. the neurofibrillary tangles and the granulovacular changes are most obvious in the hippocampus-limbic system. Milner (1967) has shown the relationship of lesions in the hippocampal area and material-specific memory disorders. The severe memory deficit presently demonstrated in the two indepen- dent A.D. samples corroborates the pathological findings.

Simard et al., (1971) and Obrist et al., (1970) found a positive correlation between the decrease in mean hemispheric CBF and the degree of dementia in groups of patients with A.D. Bower et al., (1970) and more recently Hachinski et al., (1975) found no correlation between the degree of dementia and CBF in a primary degenerative group. No correlation between degree of dementia and psychological impairment was presently found. These conflicting results are probably methodological in nature and emphasize the importance of different laboratories following similar standardized and reliable procedures in the measurement of both $\mathrm{rCBF}$ and psychological performance.

There are important implications resulting from the present findings. Different predictive statistical models were identified to differentiate the three diagnostic groups by rCBF measurement. All models identified produced excellent diagnostic accuracy. Specific statistical rCBF patterns were identified for both A.D. and M.I.D. However, some limitations of the present findings particularly those pertaining to the multivariate analysis should be pointed out. The results provide primarily a heuristic framework for additional research and practical application. Future replication studies on large samples should further evaluate the discriminatory accuracy of $\mathrm{rCBF}$ measurements. Perhaps the most important implication is the necessity for interdisciplinary research to further our understanding of the dementias.

\section{REFERENCES}

BAER, P E., MATHEW, N T, and FAIBISH, G. M. (1976). Correlates of hemispheric and regional cerebral blood flow in dementia and cerebral vascular disease. In Meyer, J S., Lechner, H., Reivich, M., and Eichhorn, O. (Eds) Cerebral Vascular Disease. 7th International Conference Salzburg, 1974. Stuttgart: Georg Thieme. (In press)

BOWER, H. M., ANDREWS, J. T., and POPE, T A. (1970) Dementia and Cerebral Blood Flow. The Medical Journal of Australia, 207:211.
COOLEY, W W and LOHNES, P R. (1971). Multivariate data analysis. New York: John Wiley and Sons, Inc.

HACHINSKI, V. C., LASSEN, N. A., and MARSHALL, J (1974). Multi-infarct dementia - a cause of mental deterioration in the elderly. Lancet, 2: 207-209

HACHINSKI, V C., ILIFF, L. D., ZILHA, E., DuBOUlay, G. H., McAllister, V. L., MARSHALL, J., ROSS RUSSELL, R. W., and SYMON, L. (1975). Cerebral blood flow in dementia. Archives of Neurology. 32: 632-637

HEISS, W D., PROSENZ, P., and ROSZUCZKY, A. (1972). Technical considerations in the use of a gamma camera, 1600 channel analyzer system for the measurement of regional cerebral blood flow. Journal of Nuclear Medicine, 13: 534-543.

HEISS, W D. (1973). Drug effects on regional cerebral blood flow in focal cerebrovascular disease. Journal of Neurological Science, 19: 461-482.

INGVAR, D. H. (1970). Cerebral blood flow in organic dementia. In J. S. Meyer, M. Rievich, H. Lechner, and O. Eichhorn (Eds.) Research on the Cerebral Circulation. 4th International Salzburg Conference, Springfield, Illinois: Charles C. Thomas.

KANNELL, W B., BLAISDELL, F W., GIFFORD, R., HASS, W. J , McDOWELL, F., MEYER, J. S., MILLIKAN, C. H., RENTZ, L. E., and SELTSER, E. (1971). Risk factors in stroke due to cerebral infarction. Stroke, 2: 423-428.

KARP, H. (1974). Dementias in adults. In A. B. Baker and L. H. Baker (Eds.) Clinical Neurology, Vol. 2, Chapter 27, Hagerstown, Maryland, Harper \& Row Publishers.

KETY, S. S. (1956). Human cerebral blood flow and oxygen consumption as related to aging. Research Publication of the Association of Nervous and Mental Disorders, 31: 35.

KLASSEN, A. C., KUSH, G. S., RESCH, J. A., LOKER, M. D., and MEYER, M. W (1971). Gamma camera evaluation of cerebral circulation using inhalation and intracarotid injection of ${ }^{133}$ Xenon. In Ross Russel, R. W. (Ed.) Brain and Blood Flow. London, Pitman, 42-47

LASSEN, N. A., MUNCK, O., and TOTTEY, E. R. (1957). Mental function and cerebral oxygen consumption in organic dementia. Archives of Neurology and Psychiatry, 77: 126.

LASSEN, N. A., FEINBERG, I., and LANE, M. H. (1960) Bilateral studies of cerebral oxygen uptake in young and aged normal subjects and in patients with organic dementia. Journal of Clinical Investigations, 39: 491

LASSEN, N. A. and INGVAR, D. (1961). The blood flow of cerebral cortex determined by radioactive Krypton. Experientia 17: 42-43.

MATHEW, N. T., MEYER, J. S., BELL, R. L., JOHNSON, P C., and NEBLETT, C. 
R. (1972). Regional cerebral blood flow and blood volume measured with the gamma camera. Neuroradiology, 4: 133-140.

MATHEW, N. T., MEYER, J. S., and HARTMANN, A. (1974). Diagnosis and Treatment of factors complicating subarachnoid hemorrhage. Neuroradiology, 6: 237-245.

MEYER, J. S., WELCH, K. M. A., PEREZ, F I., MATHEW, N. T., RIVERA, V M., GEDYE, J. L., HRASTNIK, F., MIYAKAWA, Y., ACHAR, V., ACHARI, A. N., and DODSON, R. F. (June 5-6, 1975). Neurotransmitter failure in cerebral infarction, dementia and the aging brain. Paper presented at the symposium on "The Neurobiology of Aging" New York University Medical Center.

MILNER, B. (1967) Brain mechanisms suggested by studies of the temporal lobes. In F. L. Darley (Ed) Brain Mechanisms Underlying Speech and Language. New York: Grune and Stratton.

OBRIST, W. D., CHIVIAN, E., CRONQUIST, S., and INGVAR, D. H. (1970). Regional cerebral blood flow in senile and presenile dementia. Neurology, 20: 315-322.
PEREZ, F. I., RIVERA, V. M., MEYER, J. S., GAY, J. R. A., TAYLOR, R. L. and MATHEW, N. T (1975a). Analysis of intellectual and cognitive performance in patients with multi-infarct dementia, vertebrobasilar insufficiency with dementia, and Alzheimer's disease. Journal of Neurology, Neurosurgery and Psychiatry, 38: 533-540.

PEREZ, F. I., GAY, J. R. A., and TAYLOR, R. L. (1975b) WAIS performance of neurologically impaired aged. Psychological Reports, 37: 1043-1047.

PEREZ, F. I., GAY, J. R. A., TAYLOR, R. L., and RIVERA, V. M. (1975c) Patterns of memory performance in the neurologically impaired aged. The Canadian Journal of Neurological Sciences, 2: 347-355.

PEREZ, F. I., MATHEW, N. T., RIVERA, V. M., and MEYER, J. S. (1975d). New approach to the differential diagnosis of organic dementias. Paper presented at the IV Pan American Congress of Neurology, Mexico City, October 12-17 (Abstract page No. 69).

PROSENZ, P., HEISS, W D., TSCHABITSCHER, H., and EHRMANN, L. (1974). The value of regional cerebral blood flow measurement compared to an- giography in the assessment of obstructive neck vessel disease. Stroke, 5: 19-31.

ROTH, M., TOMLINSON, B. E., and BLESSED, G. (1966). Correlation between" scores for dementia and counts of "senile plaques" in cerebral gray matter of elderly subjects. Nature, 209: 109-110.

SIMARD, D., OLESSEN, J., PAULSON, O. B., LASSEN, N. A., and SKINHO, E. (1971). Regional cerebral blood flow and its regulation in dementia. Brain, 94: 273-288.

S.OKOLOFF, L. (1953). Cerebral hemodynamics in cerebral arteriosclerosis. Journal of Gerontology. 8: 137-143.

TERRY, R. D., and WISNIEWSKI, $H$. (1970). The ulstructure of the neurofibrillary tangle and the senile plaque. In Wolstenholme, G. F. W., and O'Connor, M. (eds.) Alzheimer's Disease and Related Conditions. London: $\mathrm{J}$ and A Churchill.

TOMLINSON, B. E., BLESSED, G., and ROTH, M. (1970). Observations of the brains of demented old people. Journal of Neurological Science, 11: 205-243.

WARD, J. and JENNINGS, E. (1973). Introduction to Linear Models. Englewood Cliff, New Jersey: Prentice Hall. 